\title{
Screen-printed PZT cantilevers coated with PEUT for toluene detection. Comparison with silicon cantilevers
}

\author{
Riadh Lakhmi, Hélène Debéda, Claude Lucat \\ Université de Bordeaux, Laboratoire IMS, 351 Cours de la Libération, 33405 Talence Cedex, France \\ helene.debeda@ims-bordeaux.fr
}

\begin{abstract}
:
Self-actuated and self read-out PZT cantilevers made of Au/PZT/Au $\left(8 \times 2 \times 0.08 \mathrm{~mm}^{3}\right)$ beam layers on an alumina substrate are fabricated thanks to the association of screen-printing and sacrificial layer technique. Then, PZT cantilevers used as piezoelectric resonant type sensors are functionalized with an organic PEUT layer for toluene detection at room temperature. Due to their higher resonant frequency, cantilevers using the unusual 31 longitudinal vibration mode have higher sensitivities $(0.047 \mathrm{~Hz} / \mathrm{ppm})$ than those actuated with the classical flexural mode. These interesting results demonstrate the potentialities of printed PZT cantilevers for gas detection. Their performances are compared with those of silicon cantilevers.
\end{abstract}

Key words: PZT-cantilever, thick-layer, longitudinal vibration mode, toluene, PEUT

\section{Introduction}

For a few decades, cantilever based sensors have been attractive for gas sensing because of their high sensitivity at room temperature [1,2]. To perform detection of chemical compounds, specific sensitive layer is prior deposited on the cantilever to trap the different species. This phenomenon, which affects the cantilever mass, may induce both bending rigidity and surface stress changes. These mechanical modifications find expression in static or in dynamic modes respectively by curvature or resonance alterations [3]. Polymers are often used as sensitive layers for the detection of VOCs because adsorption is completely reversible. A wide range of polymers are employed for this purpose: PEUT, PDMS, PVA, PEI, PVP, PA, PMMA... [4,5]. More recently, silicon cantilevers have been functionalized with inorganic coatings like zeolite [6]. Generally, the resonating cantilevers used for sensing are actuated with flexural mode. However, a better sensitivity is obtained with the "in-plane" 31 longitudinal mode resonating at higher frequency than the transverse flexural modes of the classical Si cantilever having the same dimensions. We, thus, expect better sensitivity without reducing both the cantilever size and the gas interaction surface. In order to generate 31-longitudinal mode, screen-printed PZT cantilever with symmetric geometry is fabricated thanks to the association of the low cost screen-printing technology with the sacrificial layer method. Conversely to silicon cantilevers, these new types of entirely screenprinted multi-layered PZT cantilevers integrate both actuation and self read-out for sensing applications, and thus don't need any added piezoresistance or optical device. In this paper, fabrication and characterization of PEUTfunctionalized screen-printed PZT cantilevers is studied. Detection of toluene at room temperature is discussed and compared with $\mathrm{Si}$ cantilevers' performances, either coated with organic or inorganic layers.

\section{Screen-printed PZT cantilevers fabrication}

The self-actuated $8 \times 2 \times 0.1 \mathrm{~mm}^{3}$ piezoelectric cantilever is realized through screen-printing deposition associated to a sacrificial layer [7]. It is composed of a PZT layer between two gold electrodes (Fig.1).

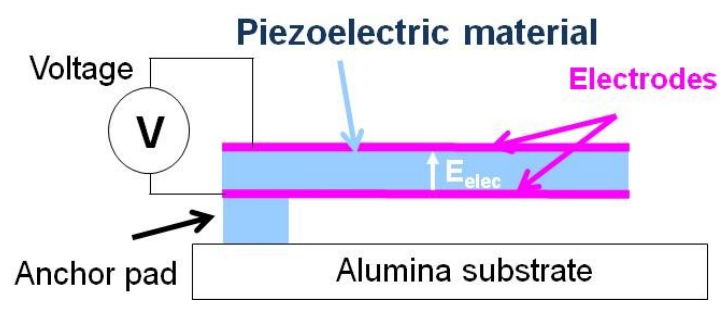

Fig.1: Scheme of the Au/PZT/Au screen-printed cantilever (80 $\mu$ m thick)

The sacrificial layer is first deposited on the substrate and polymerized at $120^{\circ} \mathrm{C}$. Then, 
bottom electrode, PZT layer and top electrode are printed successively after drying at $120^{\circ} \mathrm{C}$ during $20 \mathrm{~min}$ between each deposition (Fig.2ac). To improve densification before firing, the dried layers are isostatically pressed $1 \mathrm{~min}$ at $1 \mathrm{kbar}$. The samples are then fired 2 hours at $900^{\circ} \mathrm{C}$ in air atmosphere. Finally, dissolution of sacrificial layer is performed in the 0.9 mole. $^{-1}$ $\mathrm{H}_{3} \mathrm{PO}_{4}$ aqueous solution. Au/PZT/Au cantilevers shown on Fig.2.d are then poled at $550 \mathrm{~K}$ with an electric field of $5 \mathrm{kVcm}^{-1}$. From the porous PZT layer SEM analysis, a $70 \%$ compacity is estimated with an image calculation (Fig.2.e).

\section{Screen-printed PZT cantilevers characterization and fictionalization}

Electrical measurements of poled samples are carried out with an impedancemeter HP 4194A. They confirm the presence of "in-plane" 31-longitudinal mode (resonant frequency $\mathrm{f}_{\mathrm{r}, 31} \sim 62-64 \mathrm{kHz}$ and quality factor $\mathrm{Q} \sim 170-200$ for the $1^{\text {st }} 31$-longitudinal mode) and, thus, the cantilevers' piezoelectric behavior. The multilayered symmetry does not favor piezoelectric actuation of bending modes which can only be detected with optical measurements (displacements of few hundreds of pm). High resonant frequencies and good quality factors measured for first and second "in-plane" 31longitudinal mode justify their choice for gas sensing. These modes, easily recordable by impedance analysis, show the PZT cantilever ability for actuation/sensing with low power consumption.

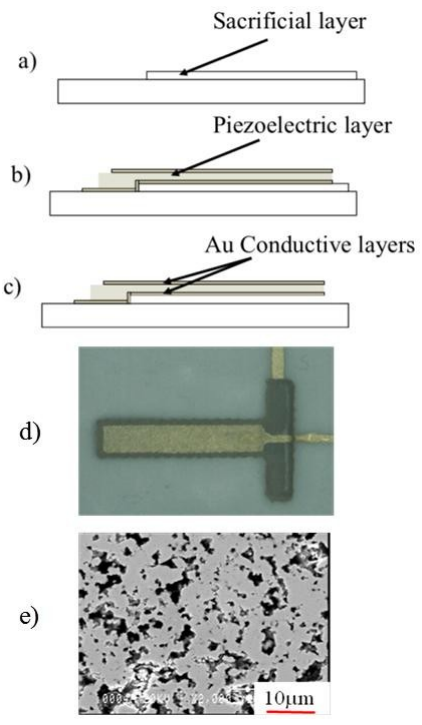

Fig. 2. Fabrication and flow chart of the PZT cantilever (a) thick-film deposition of sacrificial layer;

(b) multi-stage screen-printing Au/PZT/Au; (c) sacrificial layer elimination with $\mathrm{H}_{3} \mathrm{PO}_{4}$; (d) photo of $8 \times 2 \times 0,08 \mathrm{~mm}^{3}$ piezoelectric cantilever; and (e) SEM picture of multi-layered structure Au/PZT/Au.
PEUT (PolyEtherUreThane) is chosen because of its good partition coefficient to toluene $(K=1610)$, and sprayed on the surface of the cantilevers (thickness $30 \mu \mathrm{m}$ ) for toluene detection. This PEUT mass modifies the resonance frequency of the cantilever as confirmed by electrical measurements before and after deposition (tab.1). Using eq (1) [8] (with neglecting a stiffness change, the experimental shift has been compared with the theoretical one. Results confirm that the mass effect is predominant (tab.1).

$$
\Delta f_{31}^{(n)}=\frac{f_{31}^{(n)}}{2}\left[\frac{\Delta k_{m}}{k_{m}}-\frac{\Delta m_{m}}{m_{m}}\right]
$$

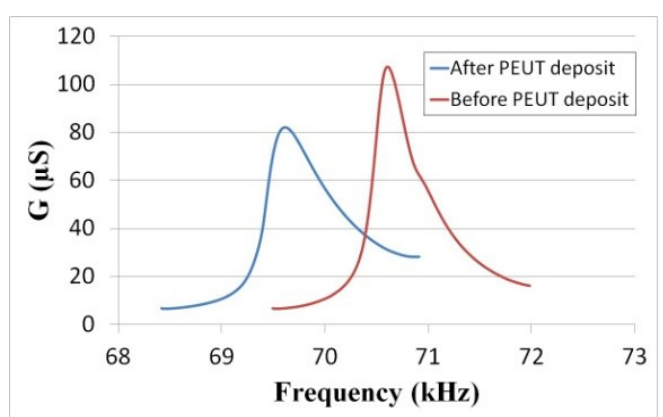

Fig.3. Resonance frequency shift due to $30 \mu m-P E U T$ Sensitive layer deposition.

Tab.1 Resonant frequency and $Q$ shifts after $30 \mu m$ PEUT deposition $(L=8 \mathrm{~mm} / w=2 \mathrm{~mm} / t=95 \mu \mathrm{m})$

\begin{tabular}{|c|c|c|c|}
\hline \multicolumn{2}{|c|}{ "In plane" 31} \\
$\begin{array}{c}\text { longitudinal Resonant } \\
\text { frequency }(\mathrm{kHz}) / \text { Quality } \\
\text { factor }\end{array}$ & \multicolumn{2}{l|}{ Resonant Shift $(\mathrm{kHz})$} \\
\hline $\begin{array}{c}\text { Before } \\
\text { PEUT } \\
\text { deposition }\end{array}$ & $\begin{array}{c}\text { After } \\
\text { PEUT } \\
\text { deposition }\end{array}$ & $\begin{array}{c}\text { Experi- } \\
\text { mental }\end{array}$ & $\begin{array}{c}\text { Theori- } \\
\text { tical }\end{array}$ \\
\hline $63,92 / 195$ & $62,89 / 169$ & $-\mathbf{1 , 0 3}$ & $\mathbf{- 0 , 9 4}$ \\
\hline
\end{tabular}

Toluene detection with PZT screen-printed PEUT-coated cantilevers

The PEUT-functionalized cantilevers are placed under a controlled nitrogen flow $(100 \mathrm{~mL} / \mathrm{min})$ and tested under different toluene concentrations (Fig. 4).

During the experiments, the impedance of the functionalized cantilevers is monitored using an HP4192A impedance meter. The whole system is controlled by a LabVIEW environment. A good reproducibility and linearity of the response to gas concentrations are obtained. Theoretical sensitivities are calculated from eq. (2) and (3) [9]:

$$
f_{r, 31}=\frac{1}{4 L} \sqrt{\frac{E_{p} t_{p}+2 E_{A u} t_{A u}+E_{s l} t_{s l}}{\rho_{p} t_{p}+2 \rho_{A u} t_{A u}+t_{s l}\left[\rho_{s l}+K C_{g}\right]}}
$$


$S_{C_{A}}=\left|\frac{d f_{31}^{(n)}}{d C_{A}}\right|=\frac{f_{31}^{(n)}}{2} \frac{K t_{C S}}{\rho_{p} t_{p}+2 \rho_{A u} t_{A u}+\rho_{C S} t_{C S}}$

where $L, t, E, \rho, C_{g}$ and $K$ are respectively the cantilever's length, thickness, Young's modulus, density, gas concentration and partition coefficient, the indexes $p, A u$ and $s /$ refer respectively to the $\mathrm{PZT}$ layer, gold electrodes and sensitive layer. The results are reported in table 1 for $L=8 \mathrm{~mm}, t_{p}=80 \mu \mathrm{m}, t_{A U}=7 \mu \mathrm{m}$, $t_{s /}=30 \mu \mathrm{m}, \quad E_{p}=38 \mathrm{GPa}, \quad \mathrm{E}_{A u}=55 \mathrm{GPa}$, $\rho_{p}=6000 \mathrm{~kg} / \mathrm{m}^{3}, \rho_{A u}=18500 \mathrm{~kg} / \mathrm{m}^{3}, \rho_{S I}=104 \mathrm{~kg} / \mathrm{m}^{3}$. Discrepancy observed between theoretical and experimental sensitivities may be attributed to inhomogeneous PEUT layers.

\section{Comparison with silicon cantilevers}

Microfabricated silicon cantilevers of rectangular shape, coated with sprayed-PEUT have been also used in previous works for gas detection. The process developed by ESIE*(http:/www.esiee.fr), calls upon 5 levels of masks [10]. The three first steps ensure the development of the strain gauge and the electrical contact. The two last steps define the geometry of the millimeter sized rectangular microcantilever. The actuation is electromagnetic. Toluene detection performances of low cost screen-printed PZT cantilevers compare well with those of silicon functionalized cantilevers tested at IMS laboratory the same way as PZT cantilevers. However; the same silicon cantilevers coated with zeolite having high specific area lead to higher sensitivities (tab.3). A more important noise, probably induced by temperature effect and/or poor densification, is also noticed in the case of screen-printed cantilevers.

Tab. 2: Sensitivities and Limit Of Detection LOD obtained with PZT screen-printed cantilever $\left(8 \times 2 \times 0.08 \mathrm{~mm}^{3}\right)$ coated with $30 \mu \mathrm{m}$ PEUT.

\begin{tabular}{|c|c|c|c|c|c|}
\hline $\begin{array}{c}\text { Resonance frequency } \mathrm{f}_{\mathrm{r}, 31} \\
(\mathrm{kHz})\end{array}$ & $\begin{array}{c}\text { Quality } \\
\text { factor Q }\end{array}$ & $\begin{array}{c}\mathrm{S}_{\text {exp }} \\
\mathrm{Hz} / \mathrm{ppm}\end{array}$ & $\begin{array}{c}\mathrm{S}_{\text {theor }} \\
\mathrm{Hz} / \mathrm{ppm}\end{array}$ & $\mathrm{S}_{\text {exp }} / \mathrm{S}_{\text {theor }}$ & $\begin{array}{c}\text { LOD } \\
=\Delta \mathrm{f}_{\text {noise }} / \mathrm{S}_{\text {exp }}\end{array}$ \\
\hline 62 & 170 & 0.047 & 0.075 & 0.6 & $26 \mathrm{ppm}$ \\
\hline
\end{tabular}
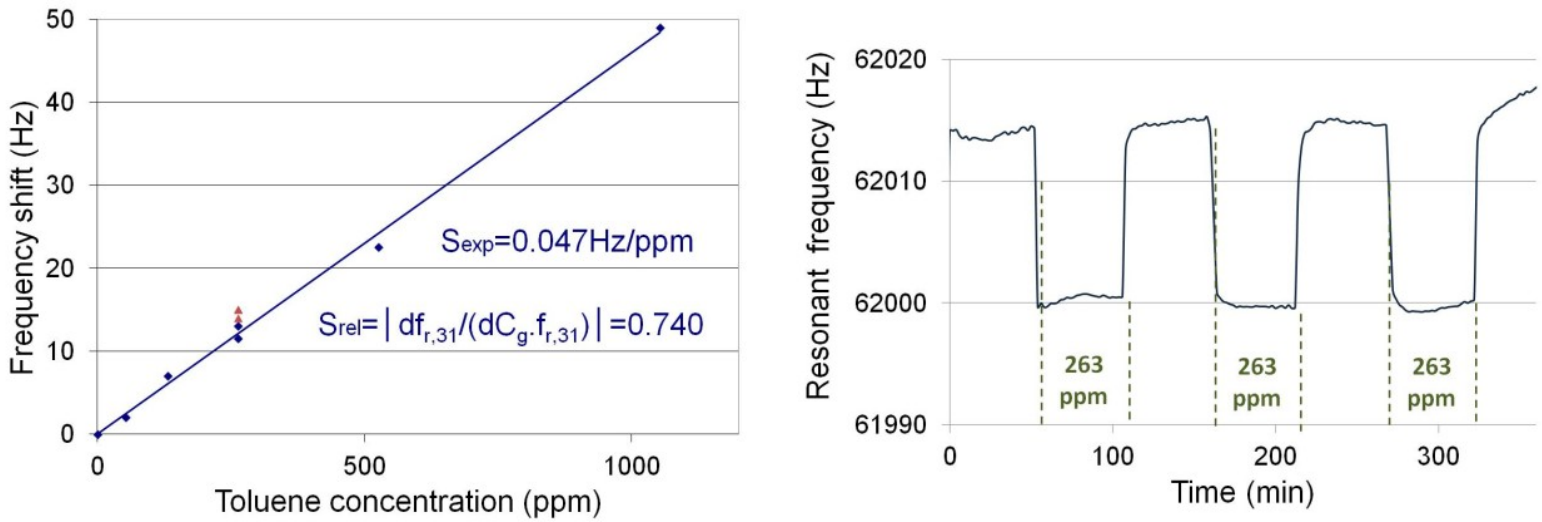

Figure 4: a) Resonant frequency shift of the $1^{\text {st }} 31$-longitudinal mode under different toluene concentrations measured with a $30 \mu \mathrm{m}$ PEUT-coated PZT cantilever $\left(8 \times 2 \times 0.08 \mathrm{~mm}^{3}\right)$ b) Repeatability of the cantilever's response to a toluene concentration of $263 \mathrm{ppm}$

Tab. 3: Performance comparison between other silicon resonant sensors

\begin{tabular}{|c|c|c|c|c|c|c|c|}
\hline Cantilever type & $\mathrm{f}_{\text {res }} /$ mode & $\mathrm{Q}$ & $\begin{array}{c}\mathrm{S} \\
\left(10^{-4} \mathrm{~Hz} / \mathrm{ppm}\right)\end{array}$ & $\begin{array}{c}\mathrm{S}_{\text {rel }} \square \\
\Delta \square \mathrm{S} / \\
\mathrm{f}\end{array}$ & $\begin{array}{c}\text { Normalized } \\
\mathrm{S}_{\text {rel }}\left(\mathrm{mm}^{-1}\right)\end{array}$ & $\begin{array}{c}\text { Noise } \\
(\mathrm{mHz})\end{array}$ & $\begin{array}{c}\text { LOD } \\
(\mathrm{ppm})\end{array}$ \\
\hline $\begin{array}{c}\text { Si } 5 \times 0.4 \times 0.059 \mathrm{~mm}^{3} \\
18 \mu \mathrm{m} \text { PEUT (IMS) }\end{array}$ & $\begin{array}{c}3 \mathrm{kHz} \\
\text { /flexural }\end{array}$ & 940 & 8.9 & 0.29 & 16 & 14 & 16 \\
\hline $\begin{array}{c}\text { PZT 8X2X0.08mm } \\
30 \mu \mathrm{m} \text { PEUT (IMS) }\end{array}$ & $\begin{array}{c}62 \mathrm{kHz} \\
\text { /longitudinal }\end{array}$ & 170 & 465 & 0.74 & 25 & 400 & 26 \\
\hline $\begin{array}{c}\text { Si } 5 \times 0.4 \times 0.059 \mathrm{~mm}^{3} \\
0.85 \mu \mathrm{m} \text { zeolite [6] }\end{array}$ & $\begin{array}{c}5 \mathrm{kHz} \\
\text { /flexural }\end{array}$ & - & 12.4 & 0.25 & 298 & 0.4 & 1 \\
\hline
\end{tabular}




\section{Conclusion}

Low cost screen-printed PZT cantilevers allow generation of unusual longitudinal 31 modes working at higher frequencies than bending modes generally used in silicon cantilevers with electromagnetic actuation [10] or piezoelectric actuation [11]. Coated with the same PEUT sensitive layer, our self excited piezoelectric cantilever present higher relative sensitivity to toluene, measured at $0.047 \mathrm{~Hz} / \mathrm{ppm}$. Limitations are nevertheless due to lower quality factor and higher noise. A combination of our self excited piezoelectric cantilever with more performant sensitive layer (inorganic layers for example) and optimized electronics (oscillator system) should give very sensitive low cost cantilever gas sensors. Indeed, results on self excited piezoelectric cantilever (bending mode at $\sim 10 \mathrm{kHz}$ ), functionalized with zeolite [11] for freon detection present a relative sensitivity of $0,24 \mathrm{~Hz} / \mathrm{ppm}$. Active carbon used as sensitive layer on our PZT cantilever is also very promising, giving relative sensitivity of $13 \mathrm{~Hz} / \mathrm{ppm}$ under benzene [12].

\section{References}

[1] M. Goeders et al., "Microcantilevers: Sensing Chemical Interactions via Mechanical Motion", Chem. Rev. 108, 522-542 (2008); doi 10.1021/cr0681041.

[2] A. Boisen, S. Dohn, SS; Keller, S. Schmidt, M. Tenge, Cantilever-like micromechanical sensors, Rep. Prog. Phys 74, 1-31, doi:10.1088/00344885/74/3/036101.

[3] Kanda, A flat type touch probe sensor using PZT thin film vibrator. Sensors and Actuators A: Physical vol. 83 (1-3) 67-75 (2000); doi:10.1016/S09244247(00)00298-3.

[4] D. Lange et al., Complementary metal oxide semiconductor cantilevers arrays on a single chip: mass sensitive detection of Volatile Organic Compounds, Anal. Chem. 74, 3084-3095 (2002); doi: 10.1021/ac011269j

[5] Y. Dong, Characterization of the gas sensors based on polymer-coated resonant microcantilevers for the detection of volatile organic compounds, Analytica Chimica Acta 671, 85-91 (2010); doi:10.1016/j.aca.2010.05.007.

[6] M.A. Urbiztondo et al., Zeolite modified cantilevers for the sensing of nitrotoluen vapours, Sensors and actuators B 137, 608-616, (2009), doi:10.1016/j.snb.2009.01.047.

[7] C. Lucat, P. Ginet,, F. Ménil, New Sacrificial Layer Based Screen-Printing Process for Free-Standing Thick-Films Applied to MEMS, Inter. Journal of microelectronic and electronic packaging, 4, 86-92, (2007); doi:10.1016/j.microrel.2008.03.016

[8] F. Lochon, I. Dufour, D. Rebière, Signal to noise ratio of resonant microcantilever type chemical sensors of a function of resonant frequency and quality factor, Sensors and actuators B chemical 102, 73-77,( 2004), doi 10.1016/j.snb.2003.10.016

[9] R.D. Blevins, Flow induced vibration of bluff structures, $P h D$ Thesis, California Institute of Technology (USA), (1973)

[10] L. Fadel, F. Lochon, I. Dufour, O. Français, Chemical sensing: millimeter size resonant microcantilever performance, Journal of Micromechanics and Microengineering, Vol. 14, S23S30, (2004); doi 10.1088/0960-1317/14/9/004

[11] J. Zhou, P. Li, S. Zhang, Y. Huang, P. Yang, M. Bao, G. Ruan, Self excited piezoelectric microcantilever for gas detection, Microelectronic Engineering 69, 37-46, (2003), doi:10.1016 /S01679317(03)00227-2

[12] R. Vázquez, R. Lakhmi, H. Debéda, F. J. Arregui, C. R. Zamarreño, M.Delgado, C. Lucat, E. Llobet, Functionalized screen-printed PZT cantilevers for room temperature benzene detection, Procedia Engineering 00 (2011) 1077 - 1080, doi: 10.1016/j.proeng.2011.12.265 